\title{
Comparative analysis of pedicle screw versus hybrid instrumentation in adolescent idiopathic scoliosis surgery
}

\author{
Omer Karatoprak • Koray Unay • Mehmet Tezer • \\ Cagatay Ozturk $\cdot$ Mehmet Aydogan $\cdot$ Cuneyt Mirzanli
}

Received: 21 November 2006 / Revised: 26 December 2006 / Accepted: 15 February 2007 /Published online: 17 April 2007

(C) Springer-Verlag 2007

\begin{abstract}
The expectations of both the patient and surgeon have been greatly revised in the last 10 years with the introduction of pedicle screws (PS) in spinal surgery. In this study, we have retrospectively evaluated and compared the results of PS instrumentation and the Hybrid System (HS), the latter consists of pedicle screws, sublaminar wire and hooks. The mean follow-up period was 60.1 months (range: 49-94 months) for the patients of the HS group and 29.3 months (range: $24-35$ months) for those of the PS group. In the HS group, pedicle screws were used at the thoracolumbar junction and lumbar vertebra, the bilateral pediculotransverse claw hook configuration was used at the cranial end of the instrumentation, sublaminar wire was used on the concave side of the apical region and the compressive hook was used on the convex side. In the PS group, PS were used on the concave sides at all levels and on the convex side of the cranial and caudal end of instrumentation, in the transition zone and at the apex. The two groups were comparable for variables such as mean age, preoperative Cobb angle, thoracic kyphosis angle, lordosis angle, coronal balance, flexibility of the curve, apical vertebra rotation (AVR), apical vertebra rotation
\end{abstract}

O. Karatoprak · M. Tezer · C. Ozturk $(\bowtie) \cdot$ M. Aydogan •

C. Mirzanli

Istanbul Spine Center, Florence Nightingale Hospital,

Abide-I Hürriyet Caddesi, No: 290,

Şişli-Istanbul, Turkey

e-mail: rezocagatay@hotmail.com

K. Unay

Goztepe Social Security Hospital,

Istanbul, Turkey
(AVT) and the number of vertebrae included in the fusion $(p>0.05)$. The parameters of values of correction, ratio of correction loss, AV derotation, AVT correction ratio, amount of blood loss, operation time, postoperative global coronal and sagittal balance, thoracic kyphosis angle and lumbar lordosis angle were measured at the last follow-up and used for comparing the HS and PS groups. There was no statistically significant difference between the groups for correction ratio, postoperative coronal balance, postoperative thoracic kyphosis and lumbar lordosis angle, operation time, amount of blood loss and number of fixation points $(p>0.05)$ The difference for the ratio of correction loss, AV derotation angle and the AVT correction ratio at the last follow-up visit and for the total follow-up period between the groups was found to be statistically significant $(p<0.05)$. Although it is possible to obtain a similar amount of correction by either instrumentation system, the loss of correction seems to be lower with the more rigid PS construction. The PS system also has a stronger effect on vertebral bodies, thereby providing better $\mathrm{AV}$ de-rotation. There was no significant difference $(p>0.05)$ between the groups in terms of correction rate, postoperative coronal and sagittal balance, operation time, blood loss and number of fixation points. This may indicate that anchor points are more important than the use - or not - of screws. Correction durability and AV de-rotation was better with PS instrumentation, while AVT was better corrected by HS instrumentation $(p<0.05)$. We propose that the reason for the better correction of AVT with HS instrumentation is the forceful translation offered by the sublaminar wire at the apical region, while the reason for the better correction durability of the PS instrumentation may be due to the fact that multiple pedicle screws which afford three-column control are better at maintaining the correction and preventing late deterioration. 
Résumé Dans la chirurgie rachidienne les attentes des patients et des chirurgiens se sont grandement modifiées depuis 10 ans, depuis l'introduction des vis pédiculaires (PS). Nous avons pour cette étude évalué de façon rétrospective et comparé les résultats de vis pédiculaires avec une instrumentation hybride (HS) utilisant à la fois des vis pédiculaires, des fils et des crochets sous laminaires. Matériel et méthode : le suivi moyen a été de 60.1 mois (49 - 94 mois) pour le groupe HS et de 29.3 mois $(24-35$ mois) pour le groupe PS. Dans le groupe HS, les vis pédiculaires ont été utilisées à la jonction dorsolombaire, thoracolombaire et au niveau lombaire avec un dispositif pédiculo transverse terminant le montage à la partie supérieure, les fils laminaires étant utilisés dans la partie concave et, dans la partie convexe avec un crochet en compression à la partie la plus apicale de la courbe. Dans le groupe vis pédiculaires, celles-ci ont été utilisées dans la partie concave à tous les niveaux et dans la partie convexe et caudale pour stabiliser l'instrumentation. Les groupes ont été très comparables en termes d'âges, d'angles de Cobb pré-opératoires, de cyphose thoracique, de lordose lombaire, de rotation et de souplesse de la courbe et de nombre de vertèbres inclus dans le montage $(\mathrm{P}>0.05)$. Les valeurs de correction, de pertes de correction, de dérotation, de pertes sanguines, de temps opératoires, de cyphose thoracique et de lordose lombaire ont été mesurées à la dernière revue des patients en comparant les deux groupes HS et PS. Résultats : il n'y a pas de différences significatives entre ces deux groupes en ce qui concerne la correction post opératoire, la cyphose thoracique post opératoire, la lordose lombaire post opératoire, le temps opératoire, les pertes sanguines et le nombre de points de fixation du matériel $(p>0.05)$. Par contre, il existe une différence en ce qui concerne les pertes de correction et l'angle de rotation, il est possible d'obtenir une correction similaire avec chaque instrumentation. Les pertes de correction sont beaucoup moins importantes avec le système vis pédicullaires, plus rigides (PS) qui entraînent une meilleure rotation. En conclusion : pour le taux de correction post opératoire, le temps opératoire, les pertes sanguines, le nombre de points de fixation les deux groupes ne montrent pas de différences significatives $(p>0.05)$. Ceci nous indique que les points de fixation du matériel sont plus importants que l'utilisation de vis. La stabilité à long terme et la dérotation sont nettement améliorées avec l'instrumentation PS, l'AVT étant mieux corrigé avec l'instrumentation HS $(\mathrm{p}<0.05)$. Nous pensons que pour avoir une meilleure correction de l'AVT comme réalisé avec l'instrumentation HS, il est nécessaire d'avoir une translation entraînée par les fils sous laminaires dans la région apicale. Par contre les raisons d'une meilleure correction et d'une meilleure stabilité dans le groupe PS sont secondaires aux multiples vis pédiculaires qui contrôlent beaucoup mieux les trois colonnes au niveau du montage avec une bonne stabilité empêchant une perte de correction secondaire.

\section{Introduction}

Segmental instrumentation in spinal surgery was first introduced by Luque in 1982 [4, 14], when he combined the rods (named after him) with sublaminar wires. The next significant development was the segmental hook-rod system designed by Cotrel-Dubousset [3, 7, 8, 12, 18]. The isola spinal instrumentation concept described by Asher in 1985 incorporated sublaminar wire and segmental apical vertebral translation (AVT) at sites other than proximal and distal anchorage ones [2, 4, 5].

The expectations of both patients and surgeons have been greatly revised in the last 10 years with the introduction of the pedicle screw (PS) instrumentation in spinal surgery $[6,8,10,16,17]$. The use of pedicle screws in treating adolescent idiopathic scoliosis (AIS) was reported by Suk et al. [15] in 1995 and Liljenquvist et al. [10] in 1997, with both sets of authors reporting a better correction, better coronal and sagittal balance and a successful fusion rate of $90 \%$ with PS usage.

In this study, we have retrospectively evaluated and compared the results of PS instrumentation and the Hybrid System (HS), which consists of pedicle screws, sublaminar wire and hooks.

\section{Material and methods}

All AIS cases treated surgically between 1998 and 2004 were evaluated; of these, 26 of the 30 patients treated using the HS system and 22 of the 28 patients treated using the PS system, all of whom attended follow-ups, were included in the study. The HS group consisted of 19 females and seven males who were treated with a pedicle screw, hook and sublaminar wire combination (Fig. 1); the PS group consisted of 17 females and five males who were instrumented by only pedicle screws (Fig. 2). The mean follow-up period was 60.1 months (range: 49-94 months) for the HS group and 29.3 months (range: 24-35 months) for the PS group.

In the HS group, pedicle screws were used in thoracolumbar junction and lumbar vertebrae, the bilateral pediculotransverse claw hook configuration was used at the cranial end of instrumentation, a sublaminar wire was used on the concave side of the apical region and a compressive hook was used on the convex side. In the PS group, pedicle screws were used on the concave sides at all levels and on convex side of the cranial and caudal end of the instrumentation, in the transition zone and at the apex. All 


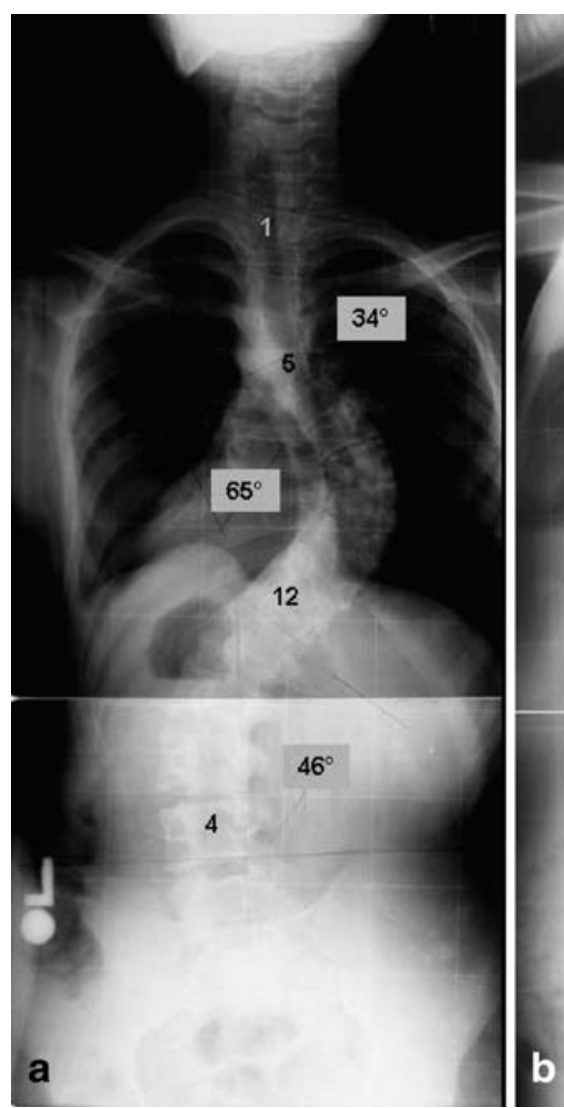

Fig. 1 A 20-year-old male manifesting adolescent idiopathic scoliosis with a triple major curve. a, b Pre-operative standing anteroposterior radiograph with a double thoracic curve (T1-T5: $34^{\circ}$, T6-L1: $65^{\circ}$, L1-L3: $46^{\circ}$ ), thoracic kyphosis of $55^{\circ}$ and lumbar lordosis of $53^{\circ}$.

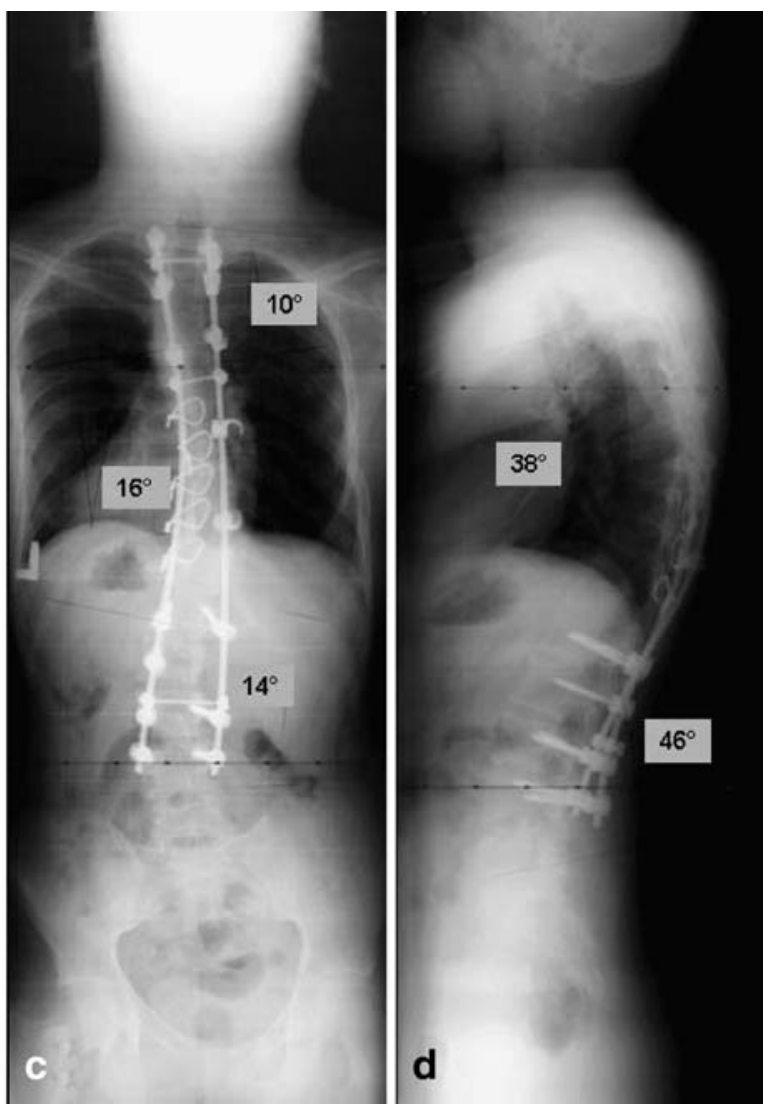

Between T2-L4, posterior instrumentation was performed with the hybrid system (HS). c, d At the postoperative measurement (20th month), the coronal Cobb angles were $10^{\circ}, 16^{\circ}$ and $14^{\circ}$, the thoracic kyphosis was $38^{\circ}$ and lumbar lordosis was $46^{\circ}$ pedicle screws were inserted transpedicularly by free-hand technique, and their positions were confirmed by intraoperative fluoroscopy. Allograft spongious chips grafts were used for all patients of both groups. Synergy (6.35-mm titanium rods; Cross Medical, Biomet) implants were used for 19 patients and Optima (6-mm titanium rods; UI Corp.) implants were used for seven patients of HS group. Synergy implants were used for 16 patients and Optima implants were used for six patients of the PS group. postoperative bracing was not employed for any of the patients. Pre-operative and last follow-up (minimum: 24 months) measurements were included in the study.

Apical vertebra rotation was determined from preoperative and postoperative computerised tomography (CT) scans including the apex of the curvature. Vertebral rotations were measured by the method of Aaro and Dahlborn [1]. AVT was determined as the distance from the vertical line drawn from the center of the S1 vertebral body (central sacral vertical line, CSVL). The global coronal balance was measured as the distance between the C7 plumb line and the CSVL on the anteroposterior (AP) radiographs. Global sagittal balance was measured as the distance from the $\mathrm{C} 7$ plumb line to the perpendicular line drawn from the superior posterior end plate of the S1 vertebral body on the lateral radiographs (sagittal sacral vertical line, SSVL). If the C7 plumb line was behind the SSVL, global sagittal balance was defined as negative; when the C7 plumb line was in front of SSVL, the global sagittal balance was defined as positive.

The two groups were comparable in terms of variables such as mean age, pre-operative Cobb angle, thoracic kyphosis angle, lordosis angle, coronal balance, flexibility of the curve from the supine bending direct graphies, AVR, AVT and the number of vertebrae included in the fusion $(p>0.05)$ (Table 1).

Values of correction, ratio of correction loss, AV derotation, AVT correction ratio, amount of blood loss, operation time, postoperative global coronal and sagittal balance, thoracic kyphosis angle and lumbar lordosis angle measured at the last follow-up were used to compare the HS and PS patients.

The results were analysed by SPSS statistical software (ver. 10.0; SPSS, Chicago, Ill.) using the Mann-Whitney $U$-test for comparison. $p$ values smaller than 0.05 were accepted as being statistically significant. 

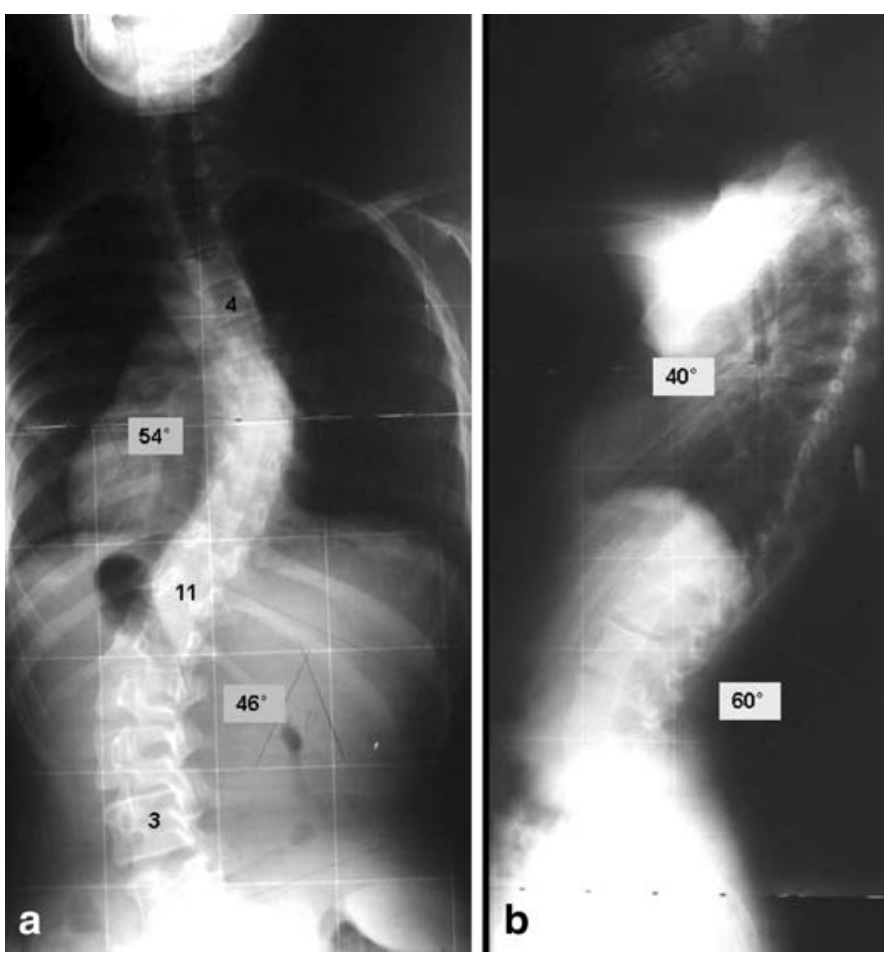

Fig. 2 A 13-year-old with adolescent idiopathic scoliosis. a, b Preoperative standing anteroposterior radiograph with a double major curve (T4-T11: $54^{\circ}, \mathrm{T} 11-\mathrm{L} 3: 46^{\circ}$ ), thoracic kyphosis of $4^{\circ}$ and a lumbar lordosis of $60^{\circ}$. Between T3-L4, posterior instrumentation was

\section{Results}

There was no statistically significant difference between the groups for correction ratio, postoperative coronal balance, postoperative thoracic kyphosis and lumbar lordosis angle,

Table 1 Comparison of the two groups of patients

\begin{tabular}{|c|c|c|c|c|c|}
\hline & \multicolumn{2}{|c|}{$\begin{array}{l}\text { Hybrid system } \\
\text { (HS) }\end{array}$} & \multicolumn{2}{|c|}{$\begin{array}{l}\text { Pedicle screws } \\
\text { (PS) }\end{array}$} & \multirow[t]{2}{*}{$\begin{array}{l}p \\
\text { value }\end{array}$} \\
\hline & Mean & Range & Mean & Range & \\
\hline Age (months) & 15.6 & $12-21$ & 14.5 & $12-17$ & 0.142 \\
\hline Pre-operative Cobb $\left(^{\circ}\right)$ & 60.5 & $45-85$ & 61.8 & $49-82$ & 0.253 \\
\hline Flexibility (\%) & 33.5 & $\begin{array}{r}20.4- \\
57.1\end{array}$ & 47.0 & $\begin{array}{r}39.0- \\
63.0\end{array}$ & 1.000 \\
\hline $\begin{array}{l}\text { Pre-operative thoracic } \\
\text { kyphosis }\left(^{\circ}\right)\end{array}$ & 27.6 & $20-42$ & 27.4 & $14-45$ & 0.078 \\
\hline $\begin{array}{l}\text { Pre-operative lumbar } \\
\text { lordosis }\left(^{\circ}\right)\end{array}$ & -37.1 & $-49 /-34$ & -37.9 & $-50 /-20$ & 0.418 \\
\hline $\begin{array}{l}\text { Pre-operative coronal } \\
\text { balance }(\mathrm{mm})\end{array}$ & 18.0 & $3-33$ & 23.6 & $12-45$ & 0.078 \\
\hline $\begin{array}{l}\text { Pre-operative sagittal } \\
\text { balance }(\mathrm{mm})\end{array}$ & 19.2 & $-4-31$ & 21.1 & $-2-28$ & 0.091 \\
\hline Pre-operative AVR $\left(^{\circ}\right)$ & 21.31 & $14-34$ & 22.13 & $15-34$ & 0586 \\
\hline Pre-operative AVT (mm) & 38.08 & $24-45$ & 36.68 & $28-45$ & 0.220 \\
\hline $\begin{array}{l}\text { Number of vertebra in } \\
\text { fusion }\end{array}$ & 12.1 & $9-16$ & 12.3 & $10-15$ & 0.717 \\
\hline
\end{tabular}

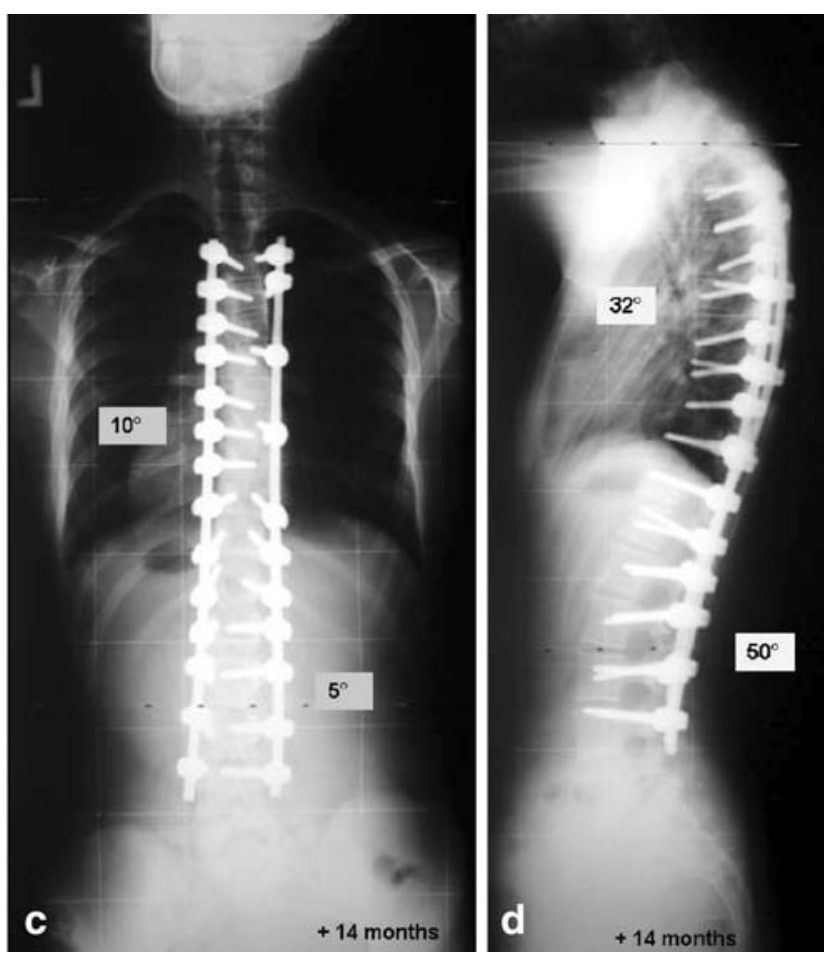

performed with PS. c, d At the postoperative measurement (14th month), coronal Cobb angles were $10^{\circ}$ and $5^{\circ}$, the thoracic kyphosis was $32^{\circ}$ and lumbar lordosis was $50^{\circ}$

operation time, amount of blood loss and number of fixation points $(p>0.05)$ (Table 2).

The difference for the ratio of correction loss, AV de-rotation angle, AVT correction ratio at the last followup visit and the total follow-up period between the

Table 2 The results of the HS and PS groups were not statistically significant $(p>0.05)$

\begin{tabular}{|c|c|c|c|c|c|}
\hline & \multicolumn{2}{|l|}{ HS } & \multicolumn{2}{|l|}{ PS } & \multirow{2}{*}{$\begin{array}{l}p \\
\text { value }\end{array}$} \\
\hline & Mean & Range & Mean & Range & \\
\hline $\begin{array}{l}\text { Correction ratio } \\
(\%)\end{array}$ & 67.7 & $\begin{array}{r}50.0- \\
81.9\end{array}$ & 70.3 & $\begin{array}{r}58.0- \\
84.6\end{array}$ & 0.226 \\
\hline $\begin{array}{l}\text { Coronal balance } \\
\text { f-up }(\mathrm{mm})^{\mathrm{a}}\end{array}$ & 12.5 & $3-20$ & 15.9 & $8-32$ & 0.096 \\
\hline $\begin{array}{l}\text { Sagittal balance } \\
\text { f-up }(\mathrm{mm})\end{array}$ & 13.1 & $4-24$ & 15.2 & $6-26$ & 0.078 \\
\hline $\begin{array}{l}\text { Thoracic kyphosis } \\
\text { f-up }\left(^{\circ}\right)\end{array}$ & 29.6 & $24-36$ & 32.5 & $24-42$ & 0.068 \\
\hline $\begin{array}{l}\text { Lumbar lordosis } \\
\text { f-up }\left(^{\circ}\right)\end{array}$ & -42.5 & $-55 /-36$ & -41.4 & $-52 /-30$ & 0.582 \\
\hline Operation time (min) & 361 & $300-420$ & 353.8 & $300-400$ & 0.459 \\
\hline Blood loss (ml) & 1813.5 & $\begin{array}{r}1500- \\
2200\end{array}$ & 1751.8 & $\begin{array}{r}1200- \\
2100\end{array}$ & 0.072 \\
\hline $\begin{array}{l}\text { Number of fixation } \\
\text { points }\end{array}$ & 18.3 & $14-22$ & 19.5 & $15-26$ & 0.064 \\
\hline
\end{tabular}

${ }^{\mathrm{a}}$ f-up, Latest follow-up 
groups were found to be statistically significant $(p<0.05)$ (Table 3).

There were no observed cases of neurological complication or implant failure. In the HS group, the most caudal screw disconnected from the rod in one case, superficial infection developed in two cases and a deep late infection developed in one case. The superficial infections resolved by medical treatment, and the deep infection required implant removal 2 years after the operation. During the implant removal operation, fusion was observed. Pedicle screws that had disconnected were re-attached to the rod at the postoperative sixth month. Fusion was extended to the T2 level in one patient of the PS group because of postoperative shoulder imbalance.

\section{Discussion}

Asher et al. [2] reported a 69\% correction, 6\% correction loss and a mean postoperative kyphosis angle of $24^{\circ}$ and lordosis angle of $54^{\circ}$ for scoliotic cases with a mean preoperative Cobb angle of $59^{\circ}$ in their study on Isola instrumentation in which a sublaminar wire, hook and pedicle screw were used in combination. The mean operation time was $341 \mathrm{~min}$, and the mean blood loss was $950 \mathrm{ml}$. In their series using Isola instrumentation with a mean pre-operative Cobb angle of $65.9^{\circ}$, Leung et al. [9] reported a $47.8 \%$ correction ratio, and measured preoperative and postoperative AVR, AVT, thoracic kyphosis and lumbar lordosis values of $2.2^{\circ}, 47.8 \mathrm{~mm}, 28^{\circ}, 40^{\circ}$ and $1.8^{\circ}, 23.1 \mathrm{~mm}, 26.7^{\circ}, 40.2^{\circ}$ respectively.

Suk et al. [16] reported a $79.6 \%$ correction for thoracic curves, an $80.5 \%$ correction for lumbar curves and a $42.5 \%$ $\mathrm{AV}$ de-rotation in his study, where he used only PS for the AIS cases. Min et al. [13] reported a $68 \%$ correction in Cobb angle and a $54 \%$ correction in AVR in his PS group of patients.

Numerous reports comparing the results of pedicle screw, hook, sublaminar wire and hybrid instrumentation have been published in recent years [3, 7, 11, 16, 18]. Liljenqvist et al. [11] compared the results of PS and hook

Table 3 Statistically significant differences between the HS and PV groups $(p<0.05)$

\begin{tabular}{lllllll}
\hline & HS & & & PS & & p value \\
\cline { 2 - 3 } & Mean & Range & & Mean & Range & \\
\hline Correction loss (\%) & 7.5 & $0-16.6$ & & 5.25 & $0-11.4$ & 0.039 \\
AV de-rotation ( $\left.{ }^{\circ}\right)$ & 14.3 & $6-29$ & & 20.5 & $10-36$ & 0.007 \\
AVT correction (\%) & 24.9 & $12-39$ & & 19.9 & $12-27$ & 0.020 \\
Follow-up (months) & 60.1 & $49-94$ & 29.3 & $24-35$ & 0 \\
\hline
\end{tabular}

instrumentation in his study published in 2002 and found similar correction rates for two groups; however, 2 years of follow-up revealed that PS was superior in terms of correction durability.

Cheng et al. [3] compared the results of PS instrumentation and apical sublaminar wire and did not observe any difference for early correction and early correction loss between the groups. AVT values for both groups were also similar. However, early postoperative thoracic kyphosis was higher in the sublaminar wire group, and this difference was even greater at the 2-year follow-up even though the global coronal and sagittal balance values of the two groups were close to each other. No difference was observed for operation time, blood loss and fusion levels between the two groups.

Kim et al. published two studies, one in 2004 in which they compared the results of PS and hook instrumentation [7] and another in 2006 in which they compared the results of PS instrumentation and HS instrumentation [18]. In the former study, they found PS instrumentation to be superior because of the better correction rate and fewer fusion levels in the study; correction loss, global coronal and sagittal balance, AVT, operation time and blood loss did not differ between the groups. In the study comparing PS and HS instrumentation, they found that the correction rate and AVT were better with PS instrumentation; global coronal and sagittal balance, operation time and blood loss were similar in two groups.

In our study, correction rate, postoperative coronal and sagittal balance, operation time, blood loss and number of fixation points were not significantly different between the groups $(p>0.05)$. In the hybrid group, we used pedicle screws at every level of the lumbar spine, and wires at almost every level of the thoracic spine and, therefore, in terms of anchor points, this group is similar to the PS group. We therefore suggest that anchor points are more important than the usage - or not - of screws. This is an important finding for those situations in which pedicle screws can not be afforded.

Correction durability and AV de-rotation was better with PS instrumentation, while AVT was better corrected by HS instrumentation $(p<0.05)$. Although it is possible to obtain a similar amount of correction with each instrumentation system, the loss of correction seems to be lower with the more rigid PS construction. The PS system has a greater effect on vertebral bodies which, in turn, provides better AV de-rotation. We believe that the reason for the better correction of AVT with HS instrumentation is the forceful translation offered by the sublaminar wire at the apical region. The reason for the better correction durability in the PS group may be due to the fact that multiple pedicle screws that afford three-column control are better at maintaining correction and preventing late deterioration. 


\section{References}

1. Aaro S, Dahlborn M (1981) Estimation of vertebral rotation and the spinal and rib cage deformity in scoliosis by computer tomography. Spine 6:460-467

2. Asher M, Lai SM, Burton D, Manna B, Cooper A (2004) Safety and efficacy of Isola instrumentation and arthrodesis for adolescent idiopathic scoliosis: two-to 12-year follow-up. Spine 29:2013-2023

3. Cheng I, Kim Y, Gupta MC, Bridwell KH, Hurford RK, Lee SS, Theerajunyaporn T, Lenke LG (2005) Apical sublaminar wires versus pedicle screws. Which provides better results for surgical correction of adolescent idiopathic scoliosis? Spine 30:2104-2112

4. Girardi FP, Boachie-Adjei O, Rawlins BA (2000) Safety of sublaminar wires with Isola instrumentation for the treatment of idiopathic scoliosis. Spine 25:691-695

5. Hall BB, Asher MA, Zang RH, Quinn LM (1996) The safety and efficacy of the Isola Spinal Implant System for the surgical treatment of degenerative disc disease. A prospective study. Spine 21:982-994

6. Halm H, Niemeyer T, Link T, Liljenqvist U (2000) Segmental pedicle screw instrumentation in idiopathic thoracolumbar and lumbar scoliosis. Eur Spine J 9:191-197

7. Kim YJ, Lenke LG, Cho SK, Bridwell KH, Sides B, Blanke K (2004) Comparative analysis of pedicle screw versus hook instrumentation in posterior spinal fusion of adolescent idiopathic scoliosis. Spine 29:2040-2048

8. Lenke LG, Kim Y, Rinella A (2002) Treatment of spinal deformity utilizing thoracic pedicle screws. Seminar Spine Surg 14:66-87

9. Leung JP, Lam TP, Ng BK, Cheng JC (2002) Posterior ISOLA segmental spinal system in the treatment of scoliosis. J Pediatr Orthop 22:296-301
10. Liljenqvist UR, Halm HF, Link TM (1997) Pedicle screw instrumentation of the thoracic spine in idiopathic scoliosis. Spine 22:2239-2245

11. Liljenqvist U, Lepsien U, Hackenberg L, Niemeyer T, Halm H (2002) Comparative analysis of pedicle screw and hook instrumentation in posterior correction and fusion of idiopathic thoracic scoliosis. Eur Spine J 11:336-343

12. Luque ER (1982) Segmental spinal instrumentation for correction of scoliosis. Clin Orthop Relat Res 163:192-198

13. Min K, Waelchli B, Hahn F (2005) Primary thoracoplasty and pedicle screw instrumentation in thoracic idiopathic scoliosis. Eur Spine J 14:777-782

14. Storer SK, Vitale MG, Hyman JE, Lee FY, Choe JC, Roye DP Jr (2005) Correction of adolescent idiopathic scoliosis using thoracic pedicle screw fixation versus hook constructs. J Pediatr Orthop 25:415-419

15. Suk SI, Lee CK, Kim WJ, Chung YJ, Park YB (1995) Segmental pedicle screw fixation in the treatment of thoracic idiopathic scoliosis. Spine 20:1399-1405

16. Suk SI, Kim WJ, Kim JH, Lee SM (1999) Restoration of thoracic kyphosis in the hypokyphotic spine: a comparison between multiple-hook and segmental pedicle screw fixation in adolescent idiopathic scoliosis. J Spinal Disord 12:489-495

17. Suk SI, Kim WJ, Lee SM, Kim JH, Chung ER (2001) Thoracic pedicle screw fixation in spinal deformities: are they really safe? Spine 26:2049-2057

18. Yongjung JK, Lenke LG, Kim J, Bridwell KH, SK Cho, Cheh G, Sides B (2006) Comparative analysis of pedicle screw versus hybrid instrumentation in posterior spinal fusion of adolescent idiopathic scoliosis. Spine 31:291-298 